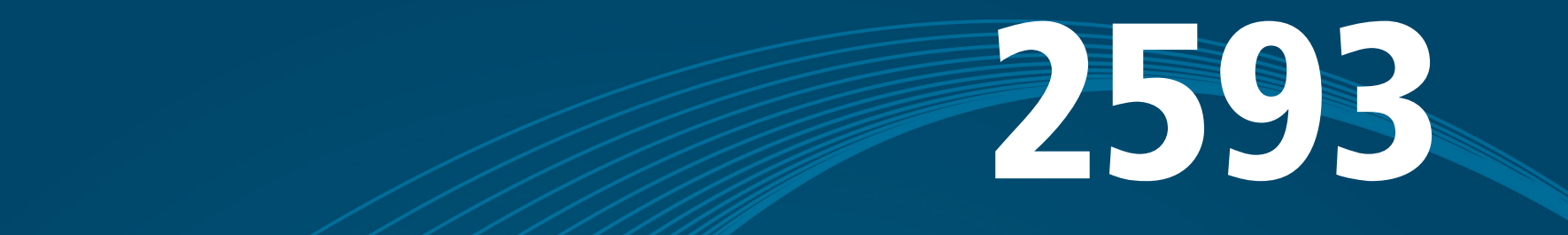

\title{
A QUESTÃO DA DESIGUALDADE NO BRASIL: COMO ESTAMOS, COMO A POPULAÇÃO PENSA E $O$ QUE PRECISAMOS FAZER
}

Pedro Cavalcante

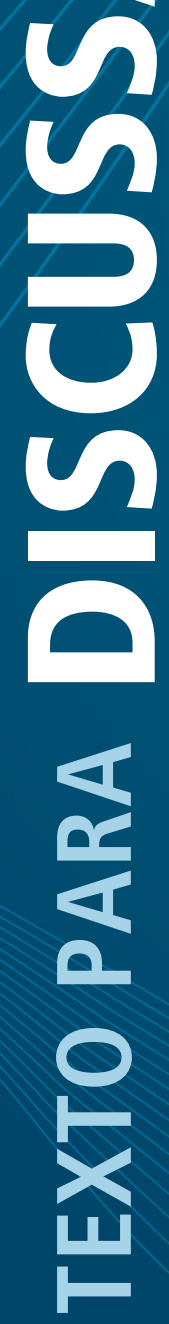





\section{TEXTO PARA DISCUSSÃO}

Brasília, setembro de 2020

\section{A QUESTÃO DA DESIGUALDADE NO BRASIL: COMO ESTAMOS, COMO A POPULAÇÃO PENSA E $O$ QUE PRECISAMOS FAZER ${ }^{1}$}

Pedro Cavalcante ${ }^{2}$

1. 0 autor agradece o suporte da assistente de pesquisa Isabella de Araújo Goellner e os comentários e sugestões de João Cláudio Pompeu, Tatiana Dias Silva, Felix Garcia e Janine Mello.

2. Especialista em Políticas Públicas e Gestão Governamental (EPPGG) do Ministério da Economia (ME), atualmente lotado na Diretoria de Estudos e Políticas do Estado, das Instituições e da Democracia (Diest) do Ipea. 


\section{Governo Federal}

Ministério da Economia

Ministro Paulo Guedes

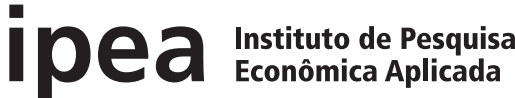

Fundação pública vinculada ao Ministério da Economia, o Ipea fornece suporte técnico e institucional às ações governamentais - possibilitando a formulação de inúmeras políticas públicas e programas de desenvolvimento brasileiros - e disponibiliza, para a sociedade, pesquisas e estudos realizados por seus técnicos.

Presidente

Carlos von Doellinger

Diretor de Desenvolvimento Institucional

Manoel Rodrigues Junior

Diretora de Estudos e Políticas do Estado, das Instituições e da Democracia

Flávia de Holanda Schmidt

Diretor de Estudos e Políticas

Macroeconômicas

José Ronaldo de Castro Souza Júnior

Diretor de Estudos e Políticas Regionais, Urbanas e Ambientais

Nilo Luiz Saccaro Júnior

Diretor de Estudos e Políticas Setoriais de Inovação e Infraestrutura

André Tortato Rauen

Diretora de Estudos e Políticas Sociais

Lenita Maria Turchi

Diretor de Estudos e Relações Econômicas

e Políticas Internacionais

Ivan Tiago Machado Oliveira

\footnotetext{
Assessora-chefe de Imprensa

e Comunicação

Mylena Fiori

Ouvidoria: http://www.ipea.gov.br/ouvidoria

URL: http://www.ipea.gov.br
}

\section{Texto para Discussão}

Publicação seriada que divulga resultados de estudos e pesquisas em desenvolvimento pelo Ipea com o objetivo de fomentar o debate e oferecer subsídios à formulação e avaliação de políticas públicas.

(C) Instituto de Pesquisa Econômica Aplicada - ipea 2020

Texto para discussão / Instituto de Pesquisa Econômica Aplicada.- Brasília : Rio de Janeiro : Ipea, 1990-

ISSN 1415-4765

1.Brasil. 2.Aspectos Econômicos. 3.Aspectos Sociais. I. Instituto de Pesquisa Econômica Aplicada.

CDD 330.908

As publicações do Ipea estão disponíveis para download gratuito nos formatos PDF (todas) e EPUB (livros e periódicos). Acesse: http://www.ipea.gov.br/portal/publicacoes

As opiniões emitidas nesta publicação são de exclusiva e inteira responsabilidade dos autores, não exprimindo, necessariamente, o ponto de vista do Instituto de Pesquisa Econômica Aplicada ou do Ministério da Economia.

É permitida a reprodução deste texto e dos dados nele contidos, desde que citada a fonte. Reproduções para fins comerciais são proibidas.

JEL: H83. 


\section{SUMÁRIO}

SINOPSE

ABSTRACT

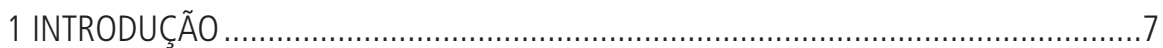

2 TEORIA SOBRE A PERCEPÇÃO DA POBREZA

E DESIGUALDADES

3 ENTRE A PERCEPÇÃO E A CONSTATAÇÃO

13

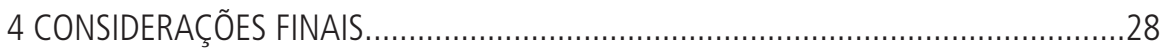

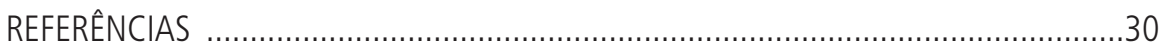

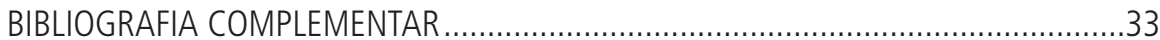





\section{SINOPSE}

Predomina um certo consenso de que a desigualdade de renda é um dos principais problemas a ser enfrentado pela administraçáo pública. Assim, este texto desenvolve uma análise inovadora das opiniôes dos cidadáos brasileiros, com base nos resultados das pesquisas de Oxfam Brasil e Datafolha, de 2017 e 2019, acerca das desigualdades, comparando convergências e divergências entre essas visóes com o conhecimento científico especializado. Os resultados demonstraram alinhamento entre o conhecimento popular e o campo de estudo, no que tange aos conceitos e diagnóstico, a perspectiva de multicausalidade e as alternativas de políticas públicas para o enfrentamento do problema. No entanto, o ordenamento desses fatores varia com os grupos de renda dos brasileiros; isto é, enquanto os mais pobres preferem políticas e investimentos públicos em setores com efeitos imediatos no seu dia a dia, os mais ricos se inclinam para soluçôes sem custos diretos a eles. Em geral, a população defende a progressividade dos impostos, isto é, os mais ricos pagando mais taxas, contudo, tendem a se excluir deste segmento populacional, ou seja, numa lógica de que 'os ricos são os outros', embora as estatísticas demonstrem o contrário. Como conclusão, o trabalho traz reflexóes novas para o avanço da compreensão desse fenômeno complexo e dinâmico, mas também para qualificar o debate sobre os limites e possibilidades de atuação da administraçáo pública.

Palavras-chave: administração pública; desigualdade de renda; políticas públicas; Estado; Brasil.

\section{ABSTRACT}

There is a consensus that income inequality is one of the main problems faced by the public administration. Thus, this article develops an innovative analysis of Brazilian citizens' opinions, based on the results of the Oxfam Brasil and Datafolha surveys of 2017 and 2019, about inequalities, comparing convergences and divergences between these views with specialized scientific knowledge. Results showed alignment between citizens' opinion and the field of study, in terms of concepts and diagnosis, the perspective of multi-causality, and the alternatives of public policies to deal with the problem. However, the ordering of these factors varies with the population's income groups. In other words, while the poorest prefer public policies and investments in sectors with 
immediate effects on their daily lives, the richest are prone to solutions without direct costs to them. In general, the population defends the progressive tax policy, i.e., the wealthiest paying higher tributes. However, they tend to exclude themselves from this population segment, in a logic that 'the rich are the others', although the statistics demonstrate the contrary. In conclusion, the paper brings new reflections to advance the understanding of this complex and dynamic phenomenon and qualify the debate on the limits and possibilities of the public administration's initiatives.

Keywords: public administration; income inequality; public policy; State; Brazil. 


\section{INTRODUÇÃO}

É crescente o consenso dentro dos governos e na academia que a desigualdade de renda é um dos principais problemas a ser enfrentado pelas naçóes nos dias atuais. Trata-se de um clássico wicked problem, ou seja, uma questão complexa, multicausal, com interpretaçôes ambíguas, muitas vezes discordantes e de difícil resolução (Levin et al., 2012). Diante de sua relevância na economia, impactos na sociedade e intrínseca relação com a política, o problema ocupa um espaço de destaque no campo de estudo da administração pública nacional e internacional.

Recentemente, a temática ganha novos contornos devido a um conjunto de estudos que demonstram um processo de agravamento da concentração de renda no mundo (Piketty, 2014; Atkinson, 2016; Piketty, Saez e Zucman, 2018; Oxfam Brasil, 2019), bem como em função da relativa convergência da academia e de organismos multilaterais acerca dos seus efeitos negativos ao desenvolvimento das naçôes (Galor, 2009; OECD, 2015; Cepal, 2018).

Embora com variaçóes significativas entre os países e limitaçóes metodológicas à mensuração precisa do fenômeno, é possível afirmar que o século XX apresentou quatro grandes momentos em relação às desigualdades. Primeiro, processo de concentração de renda até a Grande Depressão, seguido por constante redução entre 1929 e a Segunda Guerra e a relativa estabilidade até os anos 1970, especialmente, nos países da Europa continental. No último momento, a partir do fim dos anos 1970, as desigualdades de renda retomam uma trajetória ascendente (Atkinson, 2016; Piketty, Saez e Zucman, 2018).

No século XXI, esse quadro distributivo vem ainda se deteriorando - principalmente após a crise financeira de 2008 - tanto nas economias emergentes quanto nas desenvolvidas (OECD, 2015; 2018; Piketty, Saez e Zucman, 2018). Apesar da relativa estagnação econômica desse período (Végh et al., 2019), cresceu o quantitativo da população vivendo em situação de pobreza, enquanto o número de bilionários dobrou, ou seja, a riqueza global está cada vez mais concentrada (Oxfam Brasil, 2019). No caso do Brasil, pesquisas também mostram que a crise econômica afetou negativamente esses indicadores. Em outras palavras, desde 2015, as taxas de miséria e pobreza estão aumentando e o índice de Gini, depois de uma longa curva decrescente desde 2002, voltou a crescer (Assouad, Chancel e Morgan, 2018; Neri, 2018; Végh et al., 2019; LEO, 2019). 
A temática se destaca nas agendas governamental e acadêmica também devido a sua forte relação com o desenvolvimento econômico, político e social das nações. Estudos demonstram que os efeitos da concentração de renda geram barreiras a processos desenvolvimentistas. $\mathrm{Na}$ economia, o aumento da desigualdade pode afetar o mercado com o enfraquecimento da demanda, impactar negativamente a formaçáo de capital humano, reduzir a produtividade e, por conseguinte, prejudicar processos de crescimento sustentável e de longo prazo. Enquanto no campo político e social, impóe consequências como baixa coesão social, elevação da criminalidade, restriçôes ao exercício da cidadania, comprometimento da mobilidade social e fomento a posturas protecionistas (Fuentes-Nieva e Galasso, 2014; Atkinson, 2016; OECD, 2015; Cepal, 2016; 2018).

As desigualdades são resultado também das instituiçôes e políticas públicas que as modelam, com diferentes dinâmicas e padrões nas regiôes e países do mundo, envolvendo diferentes configuraçôes de regras tributárias, legislação trabalhista e características do estado de bem-estar social. Porém, apesar desse panorama preocupante e de avanços significativos nas pesquisas e estudos descritivos e explicativos sobre o fenômeno, poucos progressos vêm ocorrendo no seu efetivo enfrentamento. O combate ao problema no caso brasileiro tem sido marcado nos últimos anos, sobretudo desde 2015, por retrocessos, tanto nas políticas públicas (Lawson e Martin, 2018; Oxfam Brasil, 2018) quanto nos seus resultados no que tange aos indicadores socioeconômicos (Assouad, Chancel e Morgan, 2018; Neri, 2018).

Em síntese, a despeito do crescente processo de democratização, com mais competição política, acesso à informação e participação social no processo decisório, o problema persiste e o combate às desigualdades vem apresentando resultados abaixo do esperado. Se o campo de estudo avançou nas investigaçôes acerca do diagnóstico, de suas origens e seus efeitos deletérios à economia e sociedade, como se explica essa situação paradoxal de amplo reconhecimento do problema e baixa capacidade de resolução? Uma estratégia analítica alternativa para abordar a questấo é analisar como a sociedade entende e se posiciona sobre o problema, suas causas e soluçóes possíveis. Embora essa ênfase ainda seja incipiente e pouco explorada nas ciências sociais (Lavinas et al., 2014), esse tipo de abordagem é relevante para a compreensão sobre as restriçóes e possibilidades do apoio da populaçáo e, consequentemente, priorização do tema na agenda governamental. 
Nesse contexto, este texto visa contribuir para o avanço do estudo desse fenômeno a partir de uma perspectiva comparada entre as opiniôes dos cidadãos brasileiros acerca das desigualdades e suas convergências e/ou divergências, e o conhecimento especializado sobre o conceito, diagnóstico, causas e alternativas de açóes governamentais de enfrentamento ao problema.

O objetivo principal é analisar se existem adequaçóes nas percepçôes da população brasileira, em seus diferentes grupos de renda, com as informaçôes científicas. Para tanto, este texto para discussão compara os resultados da pesquisa Desigualdade no Brasil, de Oxfam Brasil e Datafolha, realizada em 2017 e 2019, em todo o território nacional, sobre o diagnóstico, as causas e as soluçôes com os achados da literatura produzida por acadêmicos nacionais e internacionais acerca do tema. $O$ foco é a primeira edição, que apresenta uma versão mais completa de perguntas. Todavia, de forma subsidiária, serão comentados também os resultados da pesquisa mais recente que traz uma atualização de três questôes analisadas neste texto para discussão.

Além desta introdução, o texto possui mais três seçóes. Na próxima, é abordada a literatura sobre percepçóes de pobreza e desigualdade. Em seguida, discute-se, em perspectiva comparada, aspectos relacionados ao conceito, diagnóstico percebido e mensurado, as causas da desigualdade, e também as alternativas de soluçôes e como os cidadáos reagem a elas. Já a última seção apresenta algumas consideraçôes finais e agenda futura de pesquisa.

\section{TEORIA SOBRE A PERCEPÇÃO DA POBREZA E DESIGUALDADES}

A literatura sobre as visóes da população da pobreza e desigualdades, apesar de ser um campo de estudo ainda embrionário, tende a ser dominado pelo foco em análises na percepção das elites (Reis, 2000; Reis e Moore, 2005; Silva et al., 2018; Seeking, 2018). A principal motivação reside no fato da elite econômica e política possuir mais recursos e ocupar a maioria dos postos chaves no setor privado e, principalmente, na burocracia e nos cargos eletivos, o que tende a direcionar a distribuição das riquezas da sociedade a seu próprio favor (Fuentes-Nieva e Galasso, 2014; Seeking, 2018). 
O interesse de estudo dos valores e atitudes da elite em relação à desigualdade oriunda dos trabalhos de Verba e Orren (1985) e Verba et al. (1987) que se dedicaram a pesquisar líderes nacionais (EUA, Japão e Suécia) para compreender como eles entediam a igualdade e quais seriam as suas posiçóes quanto o ideal de equidade da sociedade. Os estudos das elites consideram, portanto, que elas concentram poder e recursos e, assim, o desenho e a implementação de políticas redistributivas dependem em grande parte das preferências daqueles que estão no topo. Logo, conhecer essas preferências e os mecanismos que levam a elas é um caminho para entender como a desigualdade é reproduzida e/ou pode ser transformada.

McCarty, Poole e Rosenthal (2006) corroboram com esse argumento ao demonstrarem que a relação entre a desigualdade de renda e a polarização na determinação dos resultados de eleiçóes democráticas tendem a ser de mão dupla. Os autores, com base na realidade norte-americana, demonstram crescimento constante, desde meados dos anos 1970, da desigualdade, da polarização política e da imigração, em paralelo. Com efeito, os Republicanos se posicionaram cada vez mais polarizados e longe de açôes redistributivas e, como a maioria dos imigrantes, que constituem a parcela mais pobre da população, não pode votar, diminuem as pressóes pelo combate às desigualdades. Em outras palavras, nessa "dança da ideologia e das riquezas desiguais", a desigualdade se alimenta diretamente da polarização política na medida em que existe menos pressão política dos mais pobres por redistribuição do que dos mais ricos contra ela.

No caso do Brasil, Reis (2000) analisa a percepção de setores da elite nacional sobre a pobreza e a desigualdade, a partir de dados de survey e entrevistas em profundidade. Os resultados da pesquisa indicam que a elite brasileira demonstra grande preocupação com a pobreza e a desigualdade, sendo vistos, inclusive, como desafio à consolidação democrática do país. No entanto, o paradoxo surge na medida em que essa mesma elite não se vê como parte do problema e credita no Estado e na sua 'falta de vontade' boa parte da responsabilidade pela pobreza e desigualdade. No âmbito das soluçôes, setores do topo da sociedade brasileira tendem a depositar as fichas nos investimentos em educaçáo, como uma panaceia, o que, de acordo com Reis (2000), reflete a crença de que a melhoria das condiçóes de vida dos pobres deveria vir sem custos diretos aos não pobres. 
Essa mesma concordância na legitimidade e valorização da educação também é identificada por Reis e Moore (2005). Com base em estudos realizados em cinco países emergentes, são identificadas similaridades, mas também divergências na percepção da elite em relação à pobreza e desigualdades. Prevalece um entendimento compartilhado de que a pobreza é um problema público que deve ser objeto de açôes governamentais, assim como a visão cética quanto a capacidade dos governos em solucionar a questáo. Por outro lado, os autores demonstram que fatores como a institucionalidade dos princípios do estado de bem-estar social e a cultura política de cada nação reflete nas diferenças de opiniáo das elites quanto ao grau e a forma de intervenção estatal.

O entendimento da pobreza e desigualdades varia no tempo e espaço e, compreendê-lo é fundamental para analisar as medidas e/ou a negligência quanto ao seu enfrentamento. Essa perspectiva "plástica" desses conceitos é ponderada por Moore e Hossain (2005, p. 208):

Embora as políticas do mundo em desenvolvimento sejam muito diversas, uma regularidade é que o poder tende a se concentrar relativamente nas mãos dos tipos de pessoas que temos entrevistado - pequenas elites nacionais. Essas têm atitudes ambíguas em relação à redução da pobreza e da desigualdade e têm interesse nela. Por um lado, eles podem se beneficiar de serem poderosos e ricos no meio da pobreza, e temer as consequências de qualquer mudança significativa. Por outro lado, eles podem frequentemente perceber a pobreza como um problema e uma ameaça - ao bem-estar de 'pessoas como elas' ou à prosperidade, segurança ou dignidade de uma comunidade política e moral (nacional) maior com a qual eles se identificam.

Também em perspectiva comparada, Silva et al. (2018) procuram explorar como as elites econômicas, políticas e burocráticas interpretam os dilemas da desigualdade e da redistribuição de renda no Brasil e na África do Sul. O principal achado do estudo é a constatação de heterogeneidade das percepçôes acerca do problema e das alternativas de solução dentro das próprias elites nos países. No Brasil, predomina alta convergência das preferências das elites econômicas, em especial, em prol de uma perspectiva mais liberal, isto é, em prol de uma menor intervenção estatal. Enquanto os setores políticos e burocráticos são mais próximos entre si e se posicionam mais favoráveis às políticas públicas redistributivas.

Portanto, os estudos sobre as desigualdades na ótica das elites indicam a diversidade de perspectivas em relação a esse complexo fenômeno político, social e econômico. 
Diante disso, é razoável supor que prevaleça também heterogeneidade na visão da população como um todo. A análise de toda a população também é interessante porque possibilita identificar conflitos e divergências de visóes entre as classes sociais e traça suposiçóes sobre quem se beneficia do cenário atual. Além disso, essa estratégia analítica propicia condiçôes para avaliar apoio ou oposição à inserçấo do tema na agenda governamental, bem como o nível de suporte ou resistência por parte dos cidadáos à formulação e implementação de propostas de solução (políticas públicas).

Nesse sentido, o seminal trabalho de Lavinas et al. (2014), a partir de um amplo survey em todas as regiôes do Brasil, procurou mensurar as preferências individuais em relação às políticas redistributivas. A pesquisa se fundamenta no debate da literatura sobre os determinantes do apoio a esse tipo de açôes governamentais, que perpassa por diferentes campos de conhecimento, como economia normativa e filosofia política. Nos últimos cinquenta anos, algumas "liçóes" foram aprendidas, tais como: $i$ ) as preferências são baseadas em crenças e percepçôes que nem sempre refletem a realidade - influenciadas pela idade, estado civil, gênero e emprego -; ii) as preferências são também sociais - preocupadas com solidariedade e fraternidade -; iii) normalmente, as preferências são endógenas, ou seja, adaptam-se no tempo; e iv) proximidade social determina a intensidade da preocupação.

Os resultados do survey são bem interessantes em diferentes perspectivas. Primeiro, o brasileiro médio tende a julgar importante o papel do Estado no combate às desigualdades e na garantia do bem-estar dos cidadáos. Esse apoio é mais forte nas regióes pobres do país, especialmente Norte e Nordeste. A maioria considera que as políticas de saúde e educação devam ser universais, e também é favor da progressividade tributária, embora se posicione contrário à elevação de impostos para o financiamento desses setores. Predomina também amplo suporte às políticas focalizadas, como o Programa Bolsa Família, mas os autores ressaltam a coexistência entre a visão "desconfiada" e estigmatizada dos beneficiários e uma forte valorização a valores meritocráticos para recebimento dos benefícios (Lavinas et al., 2014).

Cabe salientar que essas visões foram captadas em uma conjuntura econômica de crescimento e estabilidade política que vivia o país no início desta década. Como mencionado acima, desde 2015, o cenário mudou drasticamente, em termos de renda da populaçáo, taxa de desemprego, indicadores de pobreza e desigualdade, o que justifica ainda mais avançarmos na análise que este artigo se propôs a realizar. 


\section{ENTRE A PERCEPÇÃO E A CONSTATAÇÃO}

Esta seção se dedica a discutir os resultados da pesquisa de Oxfam Brasil e Datafolha (2017; 2019) sobre a percepção das desigualdades, mais especificamente acerca de conceito, diagnóstico, causas e soluçôes, à luz do debate científico e especializado. Antes, porém, uma objetiva apresentação do caminho metodológica desta pesquisa se faz necessária.

\subsection{Breves parâmetros metodológicos}

As pesquisas de opinião pública de Oxfam Brasil e Datafolha, realizadas em 2017 e 2019, procuraram explorar as visôes da população brasileira sobre as diferentes dimensôes da desigualdade de renda no país. Trata-se de uma pesquisa quantitativa, com abordagem pessoal dos entrevistados em pontos de fluxo populacionais e aplicaçáo de questionário estruturado com cerca de vinte minutos de duração. A abrangência é nacional, em 129 municípios de pequeno, médio e grande porte nas cinco regiôes do país e com uma margem de erro 2 pontos percentuais (p.p.) para mais ou para menos. O universo é a populaçáo brasileira com idade entre 16 anos ou mais e amostra total de cerca de 2 mil entrevistas. Além da região e porte populacional, as especificaçóes da amostragem incluíram ainda sexo, idade, escolaridade, cor e natureza do município. ${ }^{1}$

Para fins deste texto para discussão, utilizam-se, predominante, os dados provenientes da pesquisa de 2017, pois ela tratou de um conjunto maior de questóes com ênfase nas dimensóes de interesse desta análise (por exemplo, conceito, diagnóstico, causas e soluçóes). Não obstante, três perguntas foram repetidas na versão de 2019 e, por isso, serão também objeto de consideração na análise.

De forma a aprofundar as análises, as perspectivas foram agregadas em quatro grupos, de acordo com a renda individual do cidadão. $\mathrm{O}$ foco é a renda individual proveniente da seguinte pergunta: "aproximadamente quanto você ganhou no mês passado?". Então os respondentes são divididos em cinco grupos de renda: i) mais baixa até 1 salário mínimo (SM), ${ }^{2}$ que corresponde a $45 \%$ da população; ii) baixa - de 1 a 2 SMs, com 27\%; iii) intermediária - de 2 a 3 SMs, que representa $10 \%$ da população;

1. Para mais detalhes, ver <https://bit.ly/2YyeQD0>.

2. Em 2017, o valor do SM era R\$937,00; e, em 2019, o valor chegou a $R \$ 998,00$. 
iv) alta - de 3 a 5 SMs, com 10\%; e $v$ ) mais alta - acima de 5 SMs, correspondente à 4\%. Essa agregação se justifica para facilitar a comparação entre grupos de cidadãos com rendas individuais distintas, assim é possível analisar separadamente eventuais visóes distintas dessas parcelas da população brasileira.

\subsection{Conceito e diagnóstico}

O Brasil é uma das naçóes mais desiguais do planeta (Piketty, Saez e Zucman, 2018; Cepal, 2018), no entanto, em que medida a população conhece a magnitude do problema e como ela encontra-se na estratificação social? Assim, a primeira questão da pesquisa envolve a conceituação da desigualdade no seu sentido macro (Oxfam Brasil, 2017). As respostas são bastante variadas e incluem diferentes dimensóes como a racial, sexual e cultural, entre outras. Não obstante, a maioria associa desigualdade à discriminação socioeconômica (46\%), seguido de atitudes pessoais (17\%), ou seja, falta de preocupação com os demais ou preconceito, enquanto $8 \%$ conectam com a falta de recursos e serviços. Essas respostas convergem com o caráter multidimensional do problema e também com os conceitos mais usuais; isto é, que associa desigualdade à situação de desequilíbrio entre os padróes de vida da população, seja econômico, de raça, gênero, entre outros (Cattani, 2007).

Quando perguntam em que posição o cidadão se situa numa escala de zero (mais pobre) a cem (mais ricos), a grande maioria (88\%) se coloca na metade mais pobre do país - esse valor se reduziu para $85 \%$ na edição de 2019 . Enquanto os mais abastados se posicionam na camada intermediária e até mesmo na metade mais pobre. Isso demostra uma certa dissociação com a realidade, uma vez que as classes intermediárias se consideram parte da pobreza, enquanto os mais ricos se posicionam no estrato médio do ponto de vista socioeconômico.

Além disso, 30\% da amostra acreditam que, para fazer parte dos 10\% mais ricos da população seria necessário receber mais de R $\$ 50$ mil por mês (32\% em 2019). Na prática, cerca de $\mathrm{R} \$ 3$ mil mensais já é suficiente para se enquadrar entre os $10 \%$ mais ricos do Brasil em 2017 (11\% na pesquisa seguinte). Logicamente, esse valor de renda de três SMs não significa que o indivíduo é rico, sobretudo, porque é notório que o SM no país é baixo diante das necessidades vitais básicas e às de sua família com moradia, 
alimentação, educação, saúde, lazer, vestuário, higiene, transporte e previdência social. ${ }^{3}$ No entanto, chama a atenção essa visão de que os outros são ricos e que a riqueza é muito distante da realidade do cidadáo, o que tende a repercutir no apoio ou rejeiçáo às propostas de mudanças, como veremos um pouco mais adiante.

A percepção da desigualdade também é reforçada, haja vista que se observa uma convergência de todos os segmentos acerca da afirmação de que "poucas pessoas ganham muito dinheiro e muitas pessoas ganham pouco dinheiro", ou seja, uma tradução objetiva da assimetria de renda no país. O gráfico 1 retrata essa visão, tanto da totalidade da amostra quanto nos cinco grupos de renda analisados.

GRÁFICO 1

No Brasil, poucas pessoas ganham muito dinheiro e muitas pessoas ganham pouco dinheiro (Em \%)

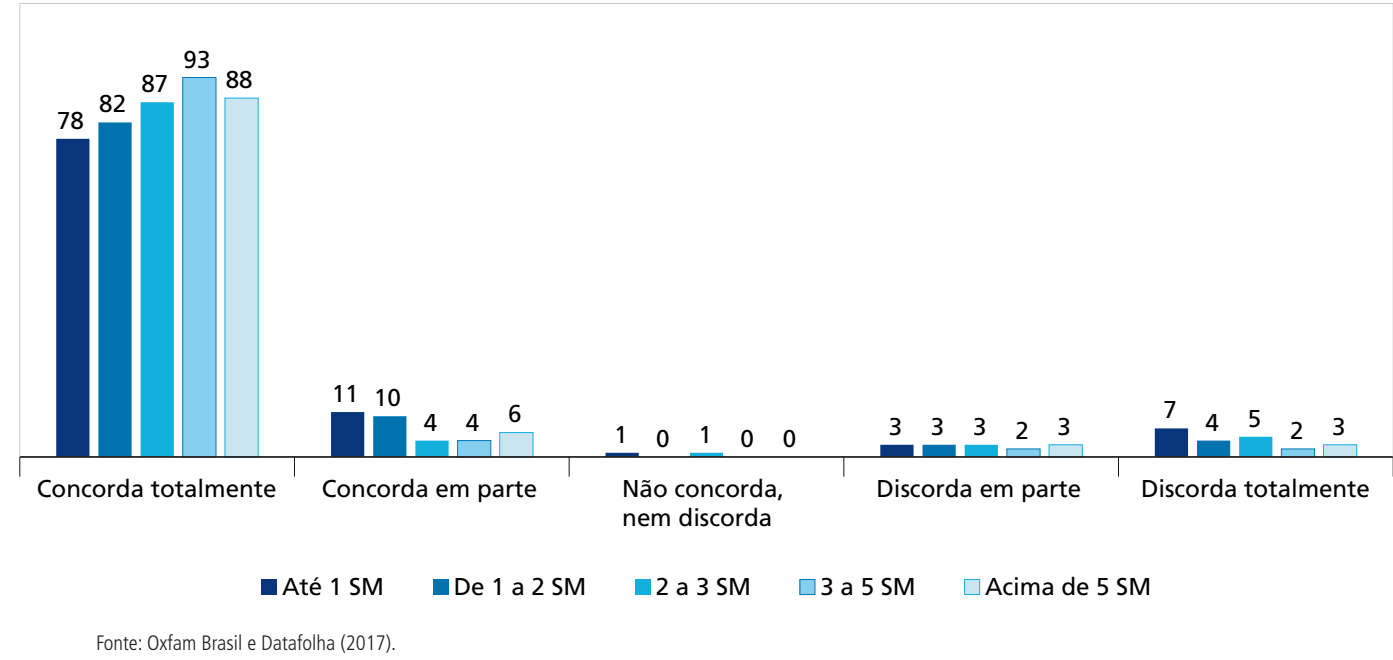

Mais de $90 \%$ da população reconhece as desigualdades de renda no país (concorda totalmente ou em parte), embora seja perceptível variações entre os grupos. Quanto mais rico, maior a concordância com a afirmação. Considerando as duas faixas de renda mais altas, ela gira em torno de 95\%. Essa perspectiva negativa da população se mantém, embora em patamar mais baixo, quando perguntados se essa diferença diminuiu recentemente, conforme exposto no gráfico 2 .

3. Para mais detalhes, ver em: <https://bit.ly/3aWo0y4>. 
GRÁFICO 2

Avaliação e perspectiva do cenário

(Em \%)

2A - A diferença entre os mais ricos e os mais pobres no Brasil diminuiu nos últimos anos

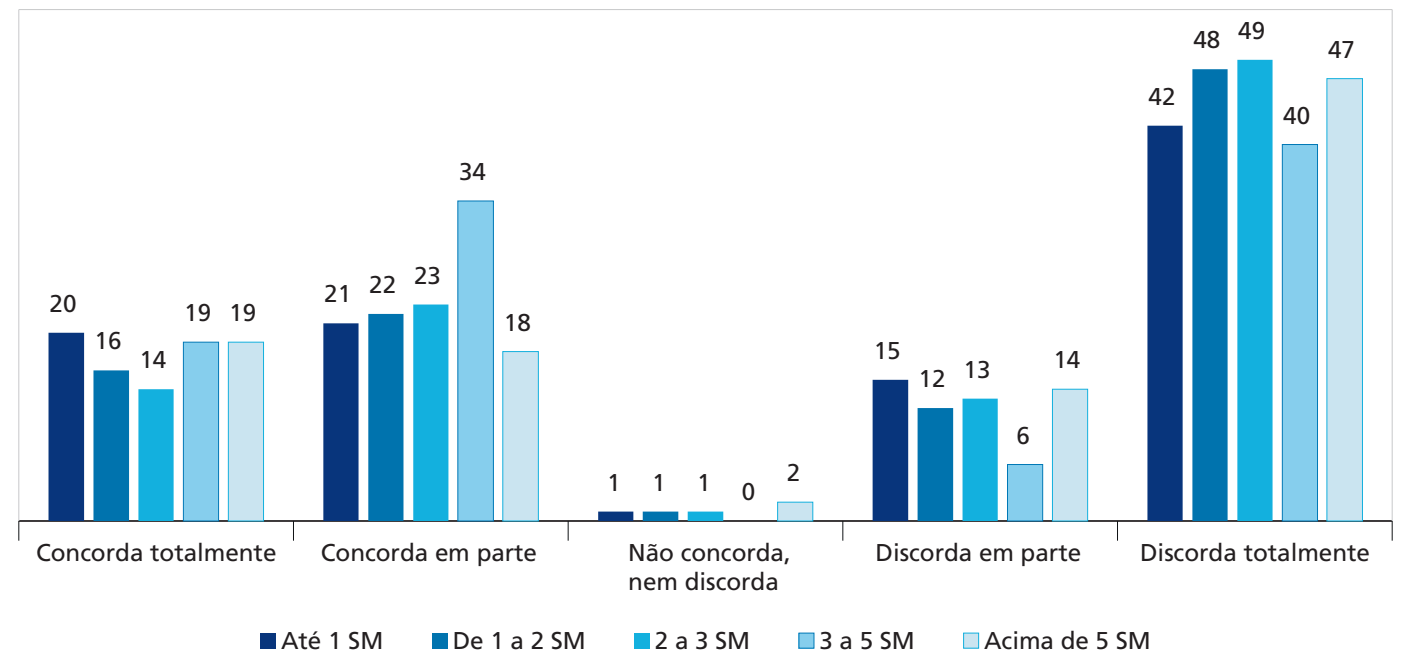

2B - Nos próximos anos, a diferença entre os mais ricos e os mais pobres no Brasil diminuirá

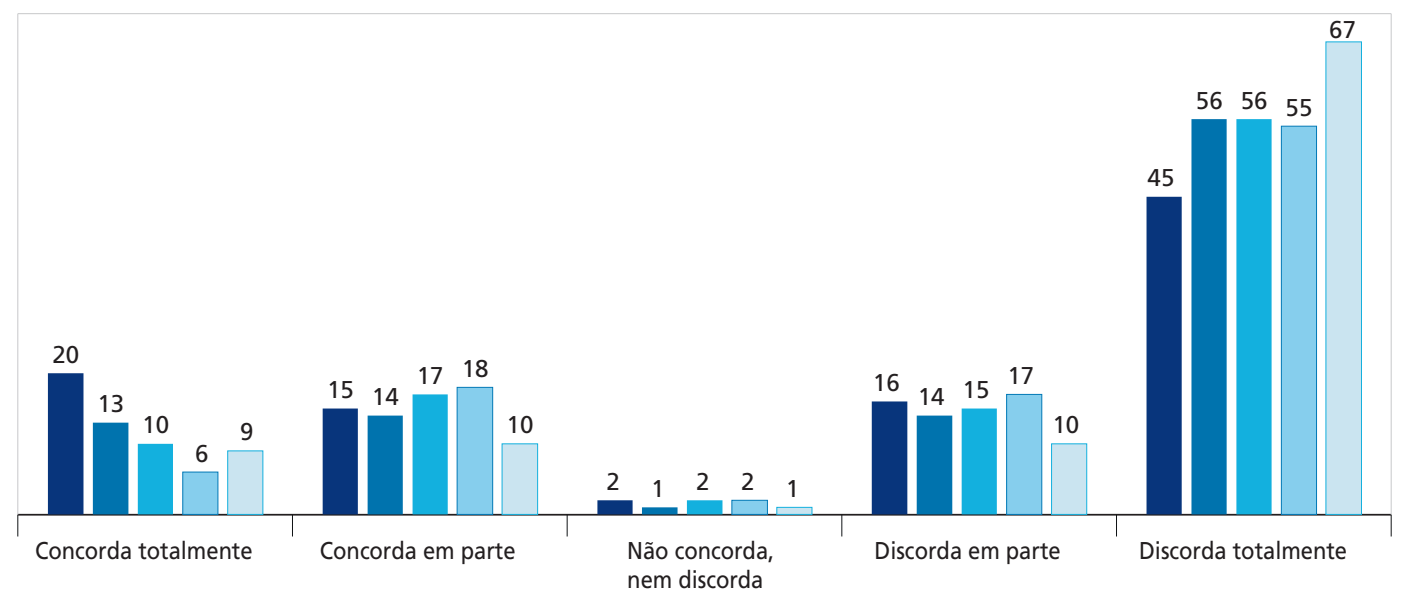

-Até 1 SM $\square$ De 1 a 2 SM $\quad 2$ a 3 SM $\square 3$ a 5 SM $\square$ Acima de 5 SM

Fonte: Oxfam Brasil e Datafolha (2017).

Observam-se mais divergências quanto à evolução dessa assimetria, embora a maioria da amostra (com exceção da faixa de 3 a 5 SMs), 54\% concorda totalmente ou em parte com a afirmação (gráfico $2 \mathrm{~A}$ ). Essa situação é bastante interessante, especialmente, porque na própria discussão do campo de estudo, não há consenso. 
No começo deste século, pesquisas com base em surveys domiciliares indicaram que a pobreza e a desigualdade de renda diminuíram devido, sobretudo, ao crescimento dos rendimentos da populaçáo de baixa renda. Contudo, ocorreu um claro arrefecimento dessa tendência nos últimos anos (Cepal, 2018; LEO, 2019). Desde 1988, o coeficiente de Gini ${ }^{4}$ teve uma queda de 16\%, passando de 0,61 para 0,51 em 2015. Todavia, trabalhos mais atuais que agregam outras fontes de dados às pesquisas domiciliares, como declaraçóes de imposto de renda e contas nacionais, mostram que os padróes de concentração de renda continuam altos e estáveis (Medeiros e Souza, 2013; 2016; Piketty, Saez e Zucman, 2018; Assouad, Chancel e Morgan, 2018). Como agravante, até mesmo estudos baseados em rendimentos da Pesquisa Nacional por Amostra de Domicílio (PNAD) ${ }^{5}$ indicam os efeitos negativos gerados pela persistente crise econômica que assola o país desde 2014. Os resultados demonstram o retorno do crescimento das taxas de miséria e pobreza, bem como o aumento do índice de Gini, após muitos anos de melhoria dessas variáveis (Neri, 2018; Oxfam Brasil, 2018).

Em relação à perspectiva para os próximos anos (gráfico 2B), novamente o pessimismo predomina. Cerca de $65 \%$, na média, concordam em parte ou totalmente com a afirmação de que a desigualdade não vai diminuir. Quanto mais rico pior o cenário futuro. Contudo, os dados da pesquisa de 2019, embora mantenha esse posicionamento, apresentam uma pequena melhora, uma vez que esse percentual se reduz para $57 \%$ (Oxfam Brasil e Datafolha, 2019). Uma possível explicação se deve ao fim da recessão, em 2018, e ao início do novo governo no âmbito federal que, geralmente, tende a carregar uma carga de otimismo nos primeiros meses, dada a sua alta popularidade após o sucesso eleitoral.

4. 0 coeficiente de Gini consiste em um número entre 0 e 1, onde 0 corresponde à completa igualdade (no caso do rendimento, por exemplo, toda a população recebe o mesmo salário) e 1 corresponde à completa desigualdade (onde uma pessoa recebe todo o rendimento e as demais nada recebem).

5. A PNAD é uma pesquisa feita pelo Instituto Brasileiro de Geografia e Estatística (IBGE) em uma amostra de domicílios brasileiros que, por ter propósitos múltiplos, investiga diversas características socioeconômicas da sociedade. 
Em suma, se por um lado, é possível perceber alinhamento entre as opinióes dos cidadãos e do campo de pesquisa acadêmica acerca do que é a desigualdade, da sua presença no Brasil e piora recente; por outro, também fica evidente uma tendência da população se posicionar como mais carente na estratificação social do que propriamente com base na mensuração dos estudos especializados. Isto é, o brasileiro reconhece o problema e sua gravidade, porém tende a se colocar como vítima e não como parte dele, fator também observado pela literatura nacional (Reis, 2000; Lavinas et al., 2014).

\subsection{As causas}

Notoriamente, as desigualdades constituem um típico wicked problem, isto é, problemas com características complexas e transversais, mas, principalmente, multicausais e com interpretaçóes variadas (Levin et al., 2012). Muito do desafio de resolver ou amenizar os efeitos negativos causados pela desigualdade de renda está atrelado à ausência de consenso quanto às suas razóes ou causas principais, o que, consequentemente, tende a culminar em propostas de soluções que podem e até mesmo agravam a situação, o que se denomina como externalidades derivadas das próprias políticas públicas.

Nesse contexto, esta subseção se dedica a descrever a visão dos cidadãos brasileiros quanto às causas das desigualdades e, em seguida, dialoga com o conhecimento científico a esse respeito. Uma primeira constatação da pesquisa é que a maioria da amostra (60\%) rechaça o mérito, seja via estudo ou trabalho, como variável explicativa das desigualdades (Oxfam Brasil e Datafolha, 2017). ${ }^{6}$ A igualdade de oportunidades entre ricos e pobres não necessariamente é vista como um determinante do sucesso profissional dos indivíduos. Parte significativa associa desigualdade a questôes estruturais da sociedade, economia e Estado. Nesse último caso, cerca de $80 \%$ da população acredita que as instituiçôes políticas, ao não funcionarem, contribuem para agravar as desigualdades, sendo que quanto maior a renda do cidadão maior tende a ser o percentual de descrença nas instituiçôes. ${ }^{7}$

6. As perguntas são: i) "no Brasil, uma pessoa de família pobre e que trabalha muito tem a mesma chance de ter uma vida bem-sucedida que uma pessoa nascida rica e que também trabalha muito"; e ii) "no Brasil, uma criança de família pobre que consegue estudar tem a mesma chance de ter uma vida bem-sucedida que uma criança nascida em uma família rica".

7. A pergunta é a seguinte: "considerando uma escala de 1 a 5, onde 1 significa não contribui e 5 contribui muito, quanto, de 1 a 5 , instituições políticas que não funcionam contribuem para a desigualdade de renda no Brasil". 
Quando questionados sobre as causas específicas da desigualdade de renda no Brasil, as respostas são bastantes variadas, porém, três causas se destacam, embora com ênfases distintas dependendo da classe de renda dos respondentes (gráfico 3).

GRÁFICO 3

Causas das desigualdades

(Em \%)

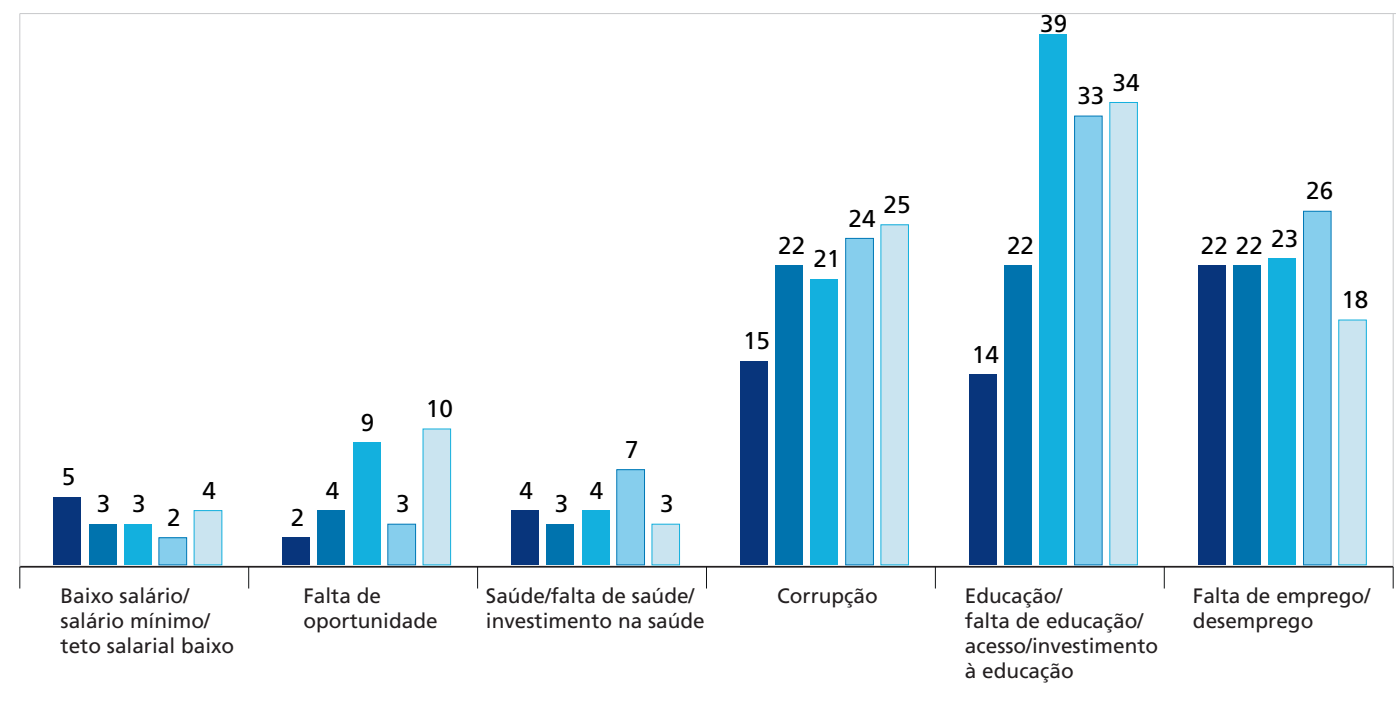

Até 1 SM De 1 a 2 SM $\quad 2$ a 3 SM $\square 3$ a 5 SM $\square$ Acima de 5 SM

Fonte: Oxfam e Datafolha (2017).

De modo geral, desemprego (22\%), educação (21\%) e corrupção (18\%) são as causas mais destacadas, enquanto outras variáveis, como falta de oportunidade, saúde e o baixo SM são bem menos citadas. Os resultados são bastante interessantes por diferentes motivos. O primeiro demonstra uma clara indicação de que os brasileiros estão, em grande medida, bastante alinhados com o campo de estudo no que tange às causas da desigualdade de renda. $\mathrm{O}$ caráter multicausal da desigualdade é sempre reforçado pela literatura e, sobretudo, a ênfase dada a essas três razóes mais mencionadas na pesquisa (Piketty, 2014; Atkinson, 2016; Oxfam Brasil, 2017; Cepal, 2016; Zúñiga, 2017; Piketty, Saez e Zucman, 2018). 
Outro aspecto relevante é a diferença entre os grupos de renda. O desemprego é visto pelos mais pobres como uma causa recorrente da desigualdade, o que é compreensível na medida em que a oscilação da renda do trabalhador em função da inserção ou não no mercado de trabalho tende a ser direta e sentida imediatamente por eles. Essa sensação é ainda agravada, pois os segmentos menos abastados da população também costumam possuir baixa poupança individual.

Apesar da educação parecer como a segunda causa mais mencionada pela populaçáo, observa-se nesse fator a maior variação entre as faixas de renda. Enquanto os mais pobres colocam a educação em terceiro lugar, com $14 \%$ das mençôes, $34 \%$ dos mais ricos do país credita na área educacional a principal causa da desigualdade de renda. Esse resultado díspar não surpreende, porque, conforme já comentado anteriormente, prevalece uma crença na elite de que a resoluçáo dos níveis de desigualdades ou de melhoria das condições de vida dos pobres poderiam advir de soluções do tipo soma zero, ou seja, os investimentos na educação provocariam efeitos positivos, incluindo mobilidade social, sem contanto, depender de esforços ou custos diretos aos não pobres (Reis, 2000; Reis e Moore, 2005). Em síntese, as respostas sobre as causas são correlacionadas pela própria perspectiva de soluçôes do cidadão, muitas vezes influenciada pela posiçáo social e como estas podem afetar direta ou indiretamente o brasileiro.

A corrupção, assim como a educação, também é citada de forma inversamente proporcional ao grupo de renda. Em outras palavras, quanto mais rico, maior o apontamento dessa como uma causa central, tendo em vista que corresponde a aproximadamente um quarto das respostas das duas faixas mais altas de renda. Quando perguntados especificamente se a "corrupção contribui muito para as desigualdades", quase $90 \%$ dos respondentes concordam com essa afirmação (gráfico 4). Não obstante, não é nenhuma surpresa a referência à corrupção como causadora de desigualdades, seja por motivação lógica ou baseada em conhecimento científico, como também por fatores de caráter conjuntural do Brasil. 
GRÁFICO 4

Contribuições para as desigualdades

(Em \%)

4A - Corrupção

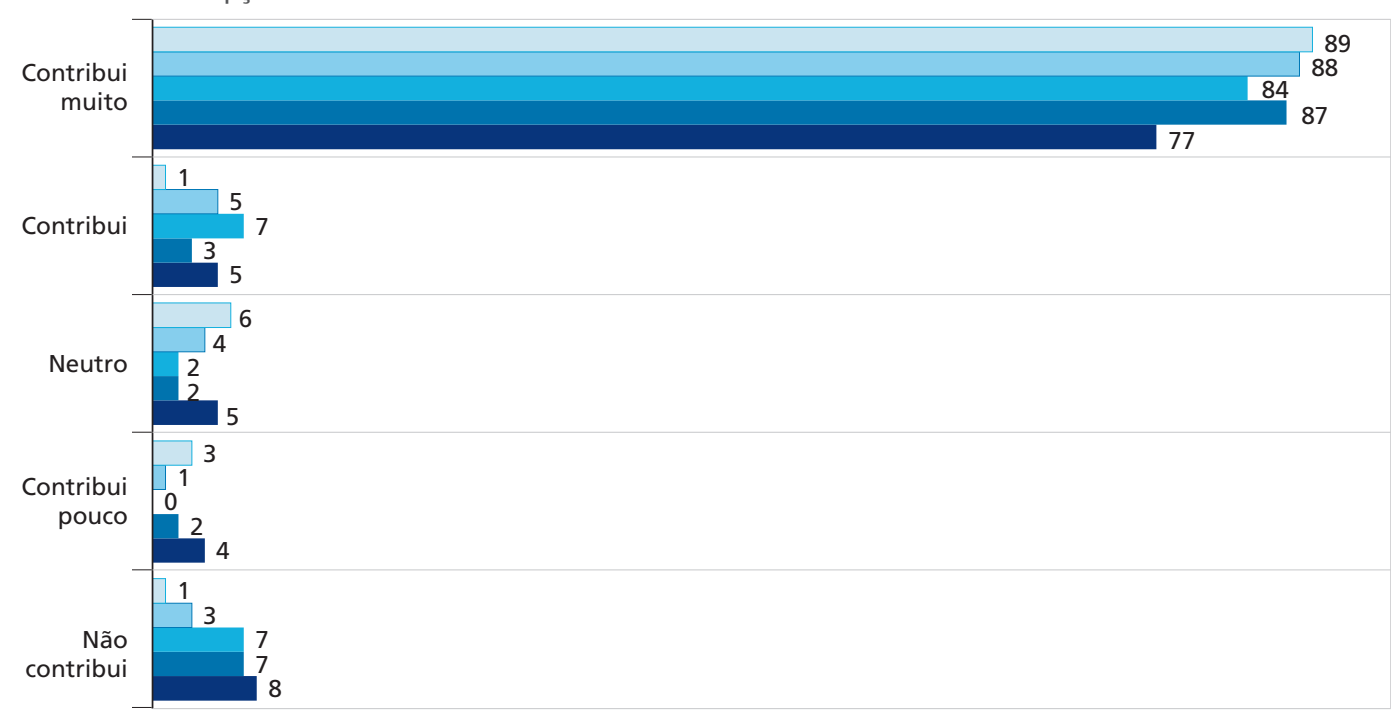

Até 1 SM De 1 a 2 SM $\quad 2$ a 3 SM $\square 3$ a 5 SM $\square$ Acima de 5 SM

4B - Falta de vagas no mercado de trabalho

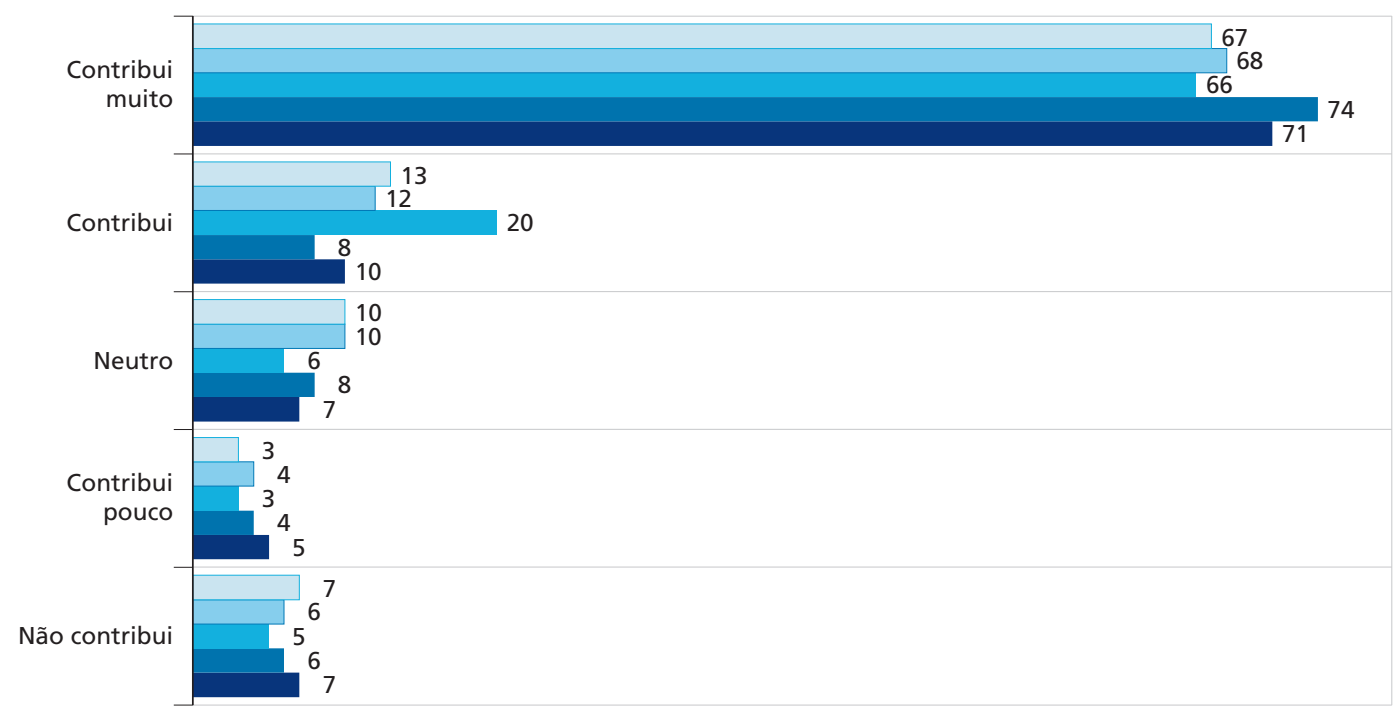

Até 1 SM $\square$ De 1 a 2 SM $\quad 2$ a 3 SM $\square 3$ a 5 SM $\square$ Acima de 5 SM 


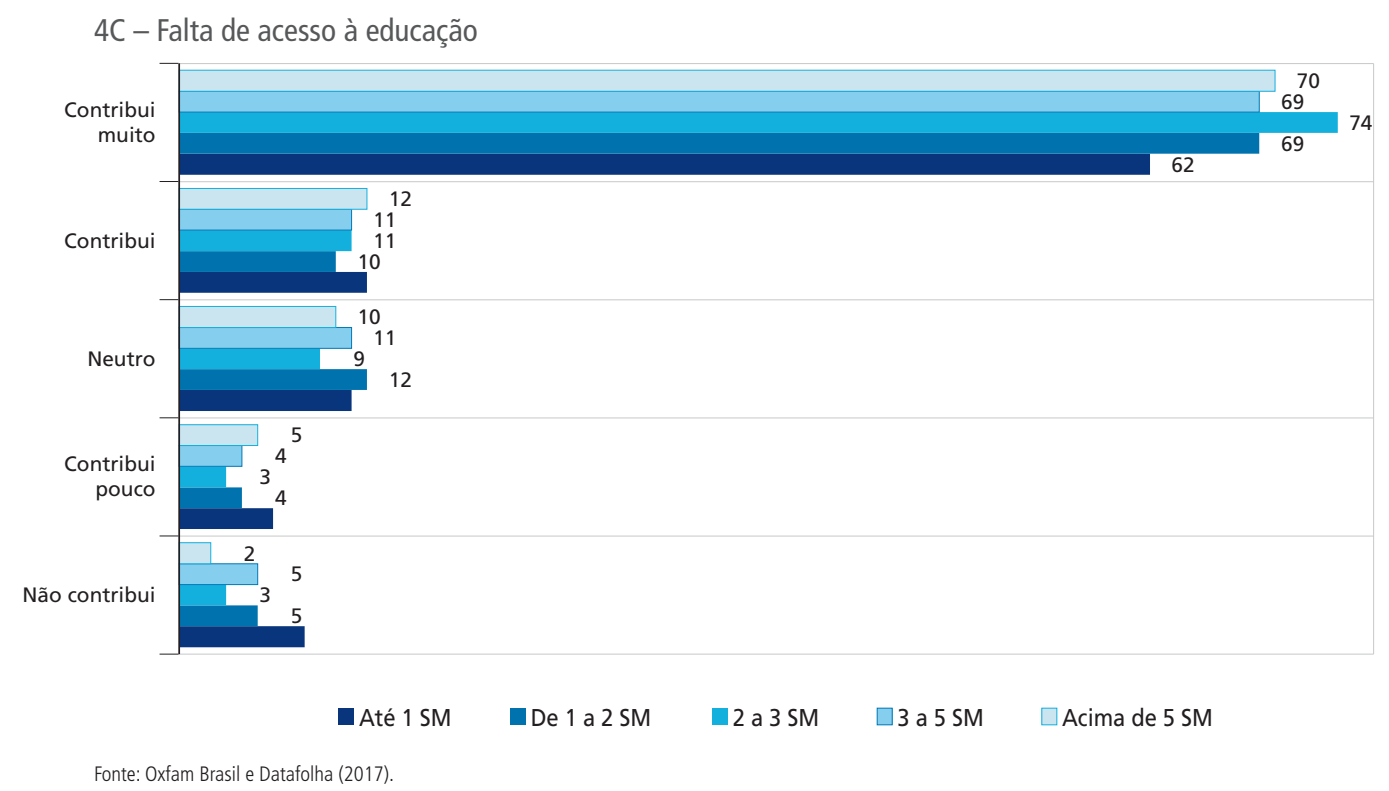

Embora menos frequente no debate internacional, os estudos sobre essa relação há tempos demonstram que o crescimento da corrupção nos países gera elevação da concentraçâo de renda (Gupta, 1998). Em outra abordagem, acadêmicos demonstram que esse relacionamento é, na prática, de mão dupla, isto é, da mesma forma que o comportamento corrupto culmina em desigualdade, ela também ajuda a promover essas práticas (Jong-sung e Khagram, 2005; Zúñiga, 2017).

No caso nacional, Sodré (2014), com foco nos municípios, mostrou que irregularidades praticadas pelas prefeituras afetam negativamente os níveis de pobreza e de desigualdade. Além disso, do ponto de vista conjuntural, é razoável supor que a associação da corrupção como um problema que afeta a situação econômica da população, uma vez que o país em crise também vem caindo no índice e no ranking da Transparência Internacional, ${ }^{8}$ que mensura a percepçáo de corrupção no setor público desde o início da Operação Lava Jato, em 2014.

8. Para mais informações, ver: <https://bit.ly/2CYnVNX>. 


\subsection{As soluções}

A última subseção analisa como as alternativas mais usuais de combate à desigualdade de renda são compreendidas pela população e em que medida as opiniôes dos cidadãos se alinham com as soluçóes preconizadas pela literatura especializada.

O primeiro aspecto central desse debate envolve o papel do Estado como protagonista do combate às desigualdades. Notoriamente, essa é uma discussão basilar no campo de estudo há séculos e que continua pautando o debate sobre "para que" e "como" a administração pública deve intervir nessa questáo. O gráfico 5 expóe que os brasileiros, majoritariamente, concordam que a reduçáo da desigualdade de renda deve ser, de fato, responsabilidade estatal e, por conseguinte, objeto de políticas públicas.

\section{GRÁFICO 5}

É obrigação dos governos diminuírem a diferença entre as pessoas muito ricas e as pessoas muito pobres

(Em \%)

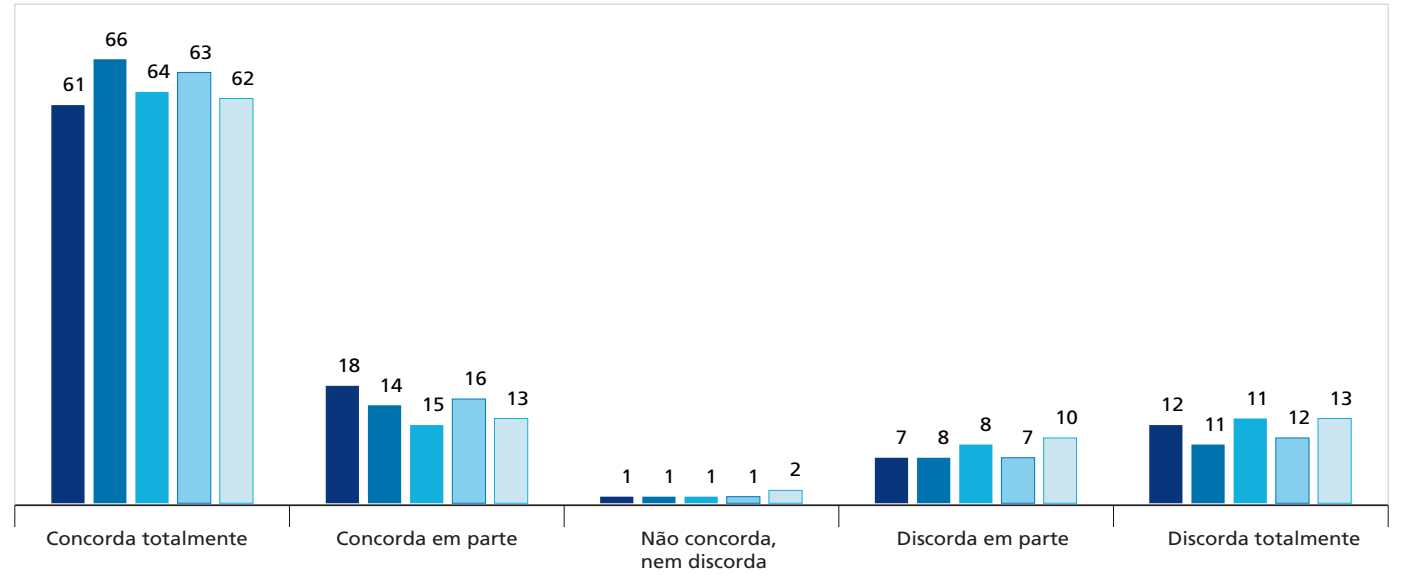

Até 1 SM $\square$ De 1 a 2 SM $\quad 2$ a 3 SM $\square 3$ a 5 SM $\square$ Acima de 5 SM

Fonte: Oxfam Brasil e Datafolha (2017).

Nota-se que a grande maioria, em torno de $80 \%$, apoia a atuação do Estado no enfrentamento à concentração de renda. Contudo, não são nítidas diferenças significativas entre os grupos de renda. Essa visão converge com uma perspectiva minimamente 
otimista de que a administração pública com seus instrumentos de políticas supostamente tem condiçóes e capacidade para combater às desigualdades, como explícito no trecho "independentemente de ser a globalização ou algum outro motivo pelo qual a desigualdade tem crescido - não há razão para se sentir desamparado: uma boa política governamental pode fazer a diferença” (OCDE, 2008, p. 7).

Se, por um lado, não existem muitos questionamentos quanto à necessidade do protagonismo estatal com sua função redistributiva nessa temática; por outro, o desafio principal é convergir na forma e intensidade dessa atuação. No caso de naçóes latino-americanas, como o Brasil, o problema se torna ainda mais preocupante na medida em que, em muitos setores, o próprio Estado exerce o papel de vilão, seja implementando políticas públicas inócuas nessa direção ou, até mesmo, gerando mais desigualdade na sociedade. A título de ilustração, de acordo com Cepal (2018), enquanto nos países da Organização para Cooperação e Desenvolvimento Econômico (OCDE), as transferências monetárias e os impostos diretos exercem efeitos redistributivos sobre o coeficiente de Gini de 19\% e 17\%, em média, na América Latina essa redução é de apenas 3 p.p.

Ademais, embora persista um relativo consenso acerca da importância da ação estatal, quando perguntados sobre quais seriam as melhores soluçóes para enfrentar o problema, os brasileiros demonstram uma visão abrangente acerca das alternativas, como também heterogênea quanto aos diferentes graus de priorizaçáo entre os grupos de renda.

Em geral, a percepção de complexidade da questão é convergente com a perspectiva das pesquisas que consideram a desigualdade como um wicked problem (Levin et al., 2012). Nessa direção, os cidadãos mantêm a coerência ao elencarem respostas que são reflexos das causas das desigualdades, tema discutido no tópico anterior. As soluções estão também alinhadas às sugestões e recomendações da academia e de organismos multilaterais (Piketty, 2014; Atkinson, 2016; Oxfam Brasil, 2017; Cepal, 2016; Piketty, Saez e Zucman, 2018). O gráfico 6 apresenta as seis alternativas mais citadas na pesquisa. 
GRÁFICO 6

Saídas para a desigualdade ${ }^{1}$

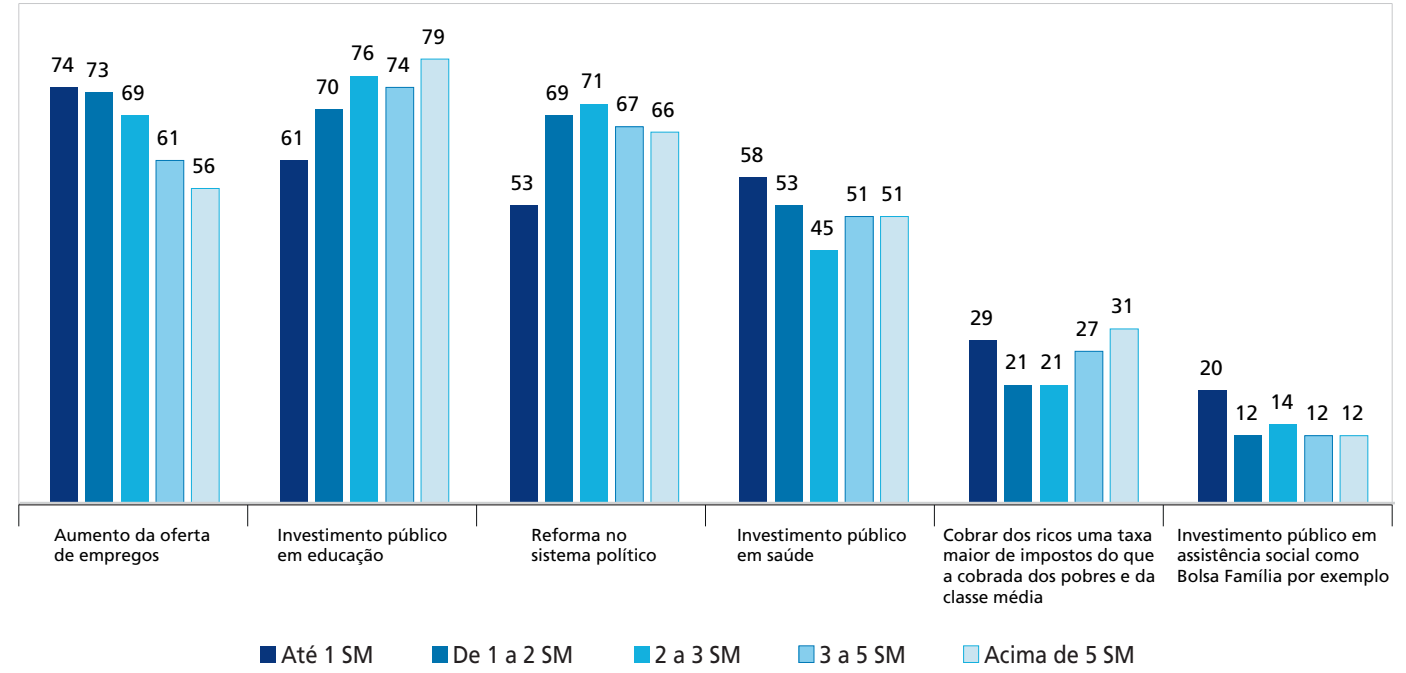

Fonte: Oxfam Brasil e Datafolha (2017).

Nota: ' Em 2019, as opções de resposta para essa questão foram alteradas. Portanto, não pôde ser comparada.

Obs.: Outras saídas foram mencionadas por $1 \%$ em todos os grupos de renda e na totalidade da pesquisa.

As duas soluções mais citadas, conforme esperado, envolvem ações na oferta de empregos, em média 71\%, e investimentos públicos em educação, em média 67\%. Nessas dimensões, mais uma vez é possível verificar discrepâncias entre os grupos de renda. Quanto ao mercado de trabalho, sem dúvida, a oferta de emprego é uma medida que impacta positivamente a equidade, porém, tão importante quanto são as melhorias nas condiçóes laborais e remuneratórias (Atkinson, 2016), que não foram mencionadas na pesquisa. Enquanto os mais pobres veem na inserção do mercado de trabalho a melhor alternativa, a elite depositava as fichas no sistema educacional como lócus de redução das desigualdades, estratégia que independe de custos diretos aos não pobres, conforme Reis (2000) e Reis e Moore (2005) já haviam ponderado.

As soluções também citadas pela população brasileira são a reforma do sistema político, aumento no investimento público em saúde, redistribuição da carga tributária e expansão da assistência social, nessa ordem - todas elas também validadas pela literatura especializada (Piketty, 2014; Atkinson, 2016; Oxfam Brasil, 2017; 2018; Cepal, 2016; 2018; Zúñiga, 2017; Piketty, Saez e Zucman, 2018). Chama a atenção que a disparidade de opinióes entre os grupos de renda se mantém em três dessas quatro alternativas. Se os mais pobres tendem a enfatizar mais a importância das áreas de saúde pública e assistência social que os mais ricos, esses últimos colocam mais ênfase 
na reforma do sistema político. Tais resultados são também esperados, haja vista que os mais carentes são os principais usuários na prestação de serviços públicos de saúde e de assistência. Além disso, é razoável supor que os mais ricos, pelo maior acesso às informaçôes e menor dependência em relação a essas políticas públicas, creditariam na reforma política um caminho para a redução da ocorrência de práticas corruptas.

Surpreendentemente, os extremos convergem no que tange a uma tributação que incida mais sobre os mais abastados como estratégia de combate à desigualdade. Essa constatação reflete o fato do Brasil, assim como a maioria dos países latino-americanos, possuir um sistema tributário marcado pela cultura do privilégio - isto é, isenções, evasão, elisão e baixo imposto sobre a renda (Cepal, 2018) -, como também pelo notório caráter regressivo na sua composição (Afonso et al., 2017; Oxfam Brasil, 2018; Piketty, Saez e Zucman, 2018; Fernandes, Campolina e Silveira, 2019).

Todavia, esse posicionamento é também contraditório. Embora três das seis soluçôes mais citadas consistam em incremento dos investimentos públicos, quando perguntados sobre aumento de impostos para o financiamento do Estado, os cidadãos tendem a rechaçar essa alternativa, a média geral é de 75\%. Quanto mais rico, maior a aversão à elevação da carga tributária (gráfico 7A).

GRÁFICO 7

Opiniões sobre o sistema tributário

(Em \%)

7A - 0 governo deve aumentar mais os impostos em geral para garantir melhor educação, mais saúde e mais moradia para os que precisam

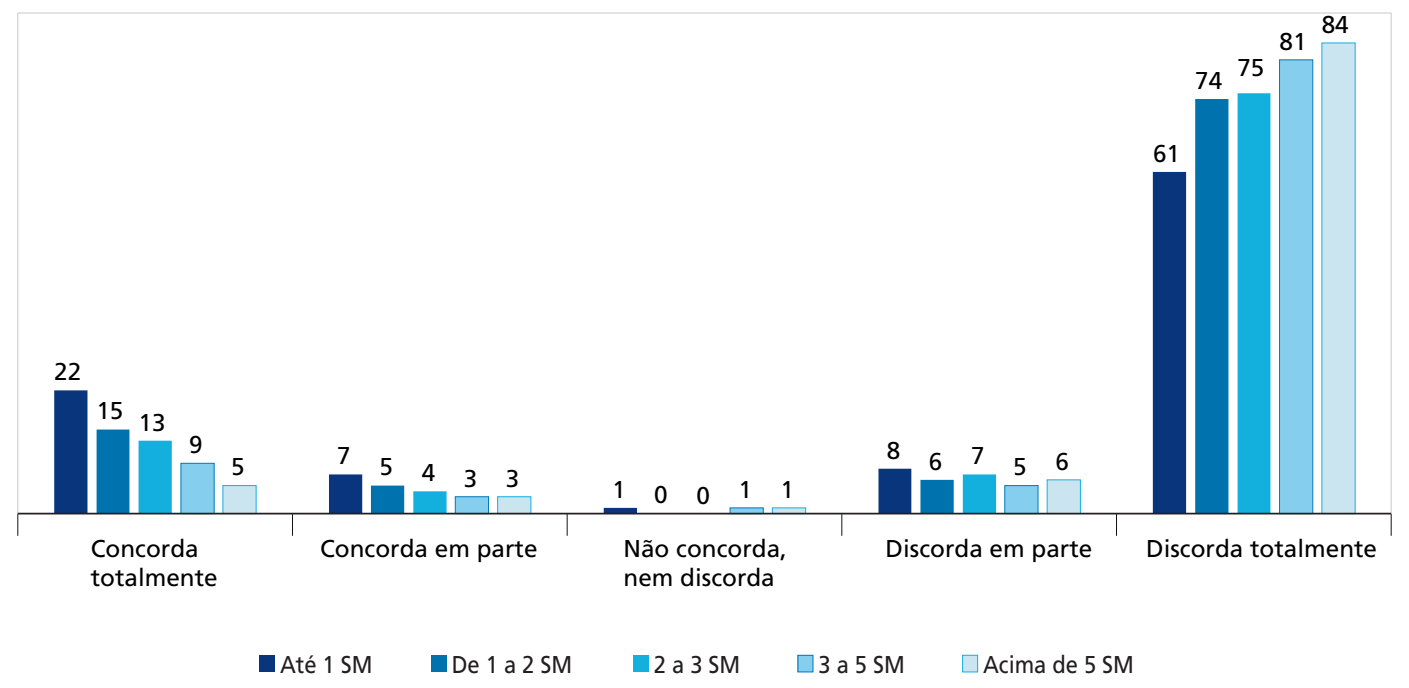


7B - Quem ganha mais deve pagar uma taxa maior de impostos do que quem ganha menos

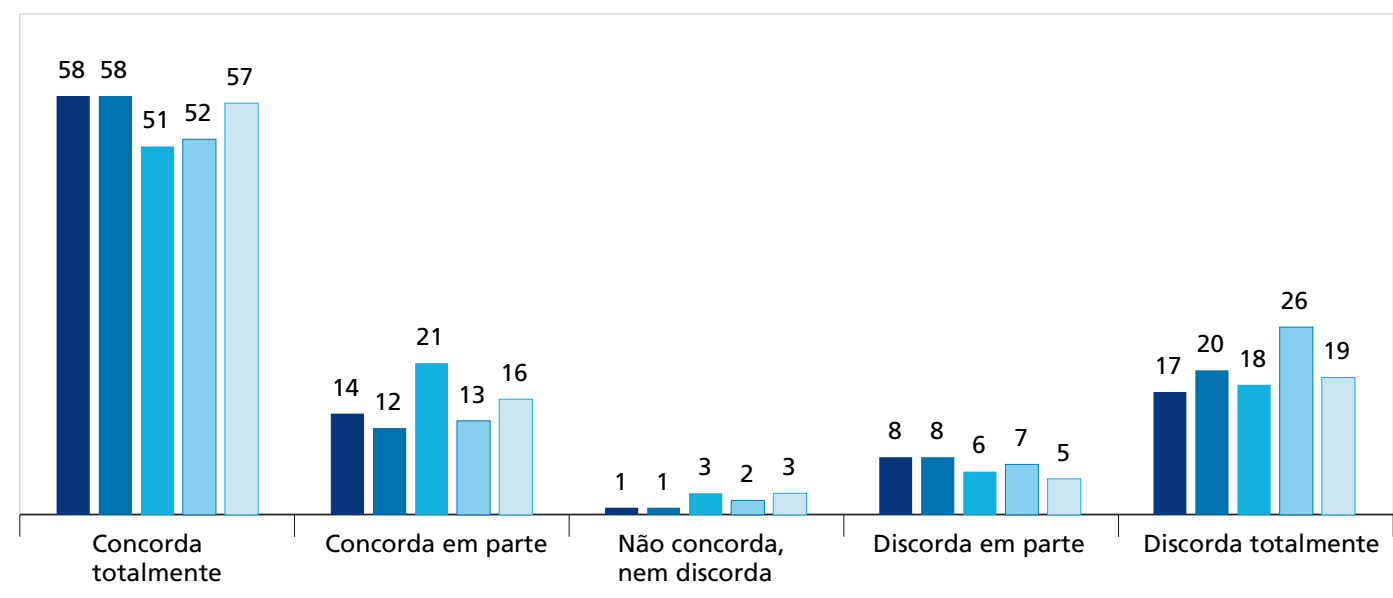

Até 1 SM De 1 a 2 SM $\quad 2$ a 3 SM $\square 3$ a 5 SM $\square$ Acima de 5 SM

7C - 0 governo deveria diminuir os impostos sobre os produtos e serviços que a população consome e compensar a diferença com aumento de impostos sobre a renda dos mais ricos

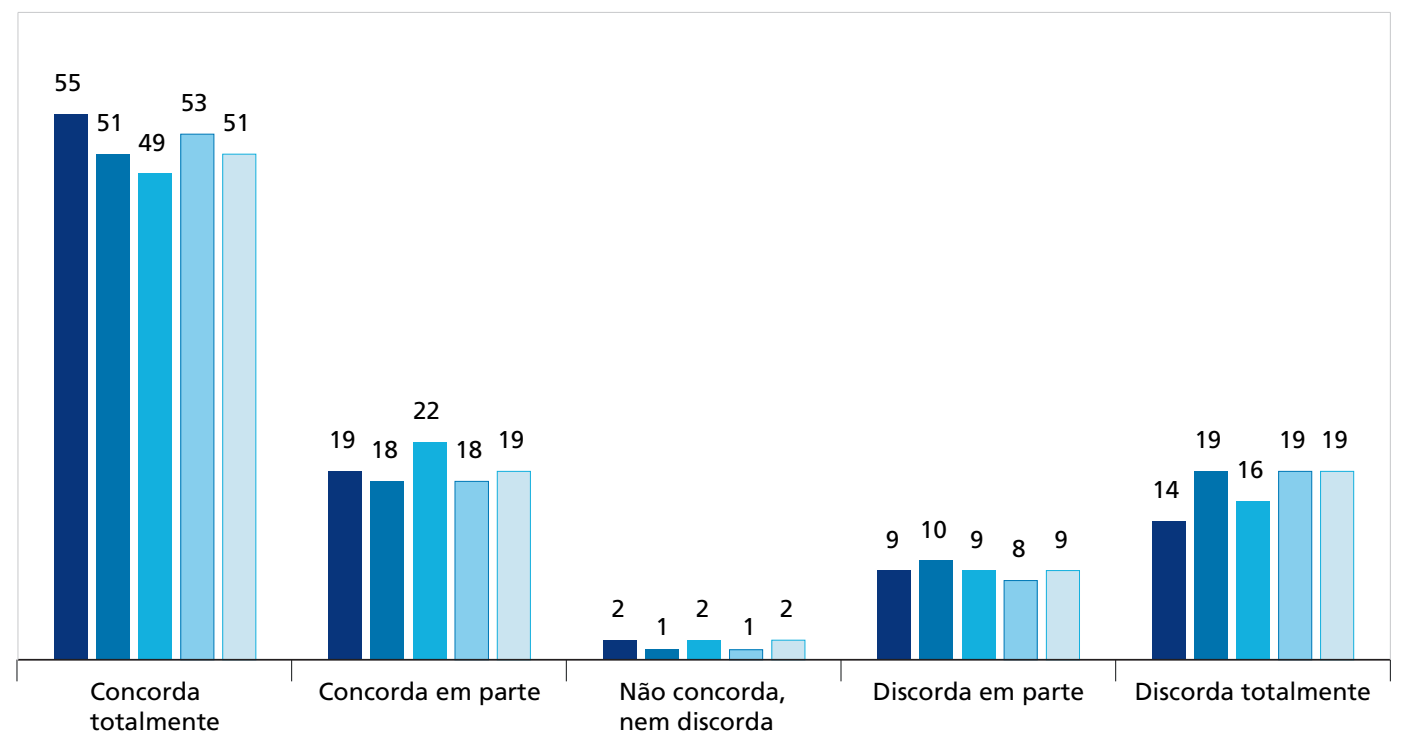

Fonte: Oxfam Brasil e Datafolha (2017).

Além disso, como retratado no gráfico 7 , o brasileiro dá sinais de que reconhece a regressividade da tributaçấo no país, ou seja, maior peso proporcional dos impostos nas parcelas da populaçáo mais carente (gráficos 7B e 7C). Essa característica assimétrica do sistema tributário no Brasil é recorrentemente mencionada não apenas como um problema, mas também como um agravante das desigualdades (Afonso et al., 2017; Oxfam Brasil, 
2018; Piketty, Saez e Zucman, 2018; Fernandes, Campolina e Silveira, 2019). Sem dúvida, há uma convergência com a literatura especializada tanto no diagnóstico quanto na proposição de melhorias da configuração dos impostos (Atkinson, 2016; Oxfam Brasil, 2018; OCDE, 2008; 2018; Cepal, 2018). Nessas três questôes, os resultados da pesquisa de 2019 sinalizam também para um aumento na concordância da população em favor do aumento de impostos para financiar políticas sociais e para a progressividade tributária (Oxfam Brasil e Datafolha, 2019).

Contudo, cabe ponderar que a formulação das perguntas tende a gerar uma propensão a respostas consideradas mais "justas” por parte dos cidadãos. Aliado a isso, esse senso de justiça em prol de uma maior progressividade na cobrança de impostos, como exemplo de "mais taxação aos mais ricos", é limitado, sobretudo, nos grupos de maior renda. Conforme vimos anteriormente, a maioria da populaçáo, mesmo o segmento de renda mais elevado, não se considera como como parte da elite econômica. Logo, defende a tributação dos mais abastados, contanto que não sejam incluídos nesse segmento.

\section{CONSIDERAÇÕES FINAIS}

A questão da desigualdade por si só já consiste e um tema extremamente relevante para a administração pública, uma vez que a sua redução é um dos quatro objetivos fundamentais da Constituiçáo Federal de 1988 (CF/1988). O país ainda é signatário, junto com outras 192 naçóes, dos Objetivos de Desenvolvimento Sustentável (ODS), 9 que estabelecem a mesma meta constitucional. Recentemente, as crises econômicas doméstica e internacional agravaram as desigualdades e sua "irmã gêmea", a pobreza, o que enseja mais pressóes da sociedade por políticas públicas efetivas.

Por um lado, são notórios os progressos no campo de estudo em termos de investigaçóes sobre mensuraçáo da inequidade, origens, impactos sobre o desenvolvimento econômico e social das naçóes, bem como alternativas de enfrentamento. Por outro, evoluímos pouco na explicação do porquê, em um contexto democrático com competição política, mesmo tendo mais acesso à informação e participação social

9. Para mais detalhes, ver: <https://bit.ly/3b3y8w0>. 
no processo decisório, o setor público vem sendo incapaz de efetivamente resolver ou amenizar o problema. As questôes que norteiam as pesquisas, portanto, devem ser tão abrangentes e complexas como o próprio fenômeno da desigualdade e, logo, a abordagem de como a sociedade entende e se posiciona é apresentada como uma estratégia analítica e interessante para compreender essa situação paradoxal. Logo, a análise almejou comparar as convergências e/ou divergências entre as opinióes dos cidadãos brasileiros e o conhecimento especializado sobre o conceito, diagnóstico, causas e alternativas de açóes governamentais de enfrentamento ao problema.

Em geral, os resultados foram bastante instigantes. Primeiro, as análises demonstraram alinhamento entre conhecimento popular e o campo de estudo, no que tange aos conceitos e ao diagnóstico do problema no país. A maioria da população também concorda que se trata de uma responsabilidade estatal atacar a alta concentraçáo de renda, via investimentos e políticas públicas, embora o pessimismo prevaleça tanto em relação à situação quanto à capacidade do Estado em modificar o status quo a partir das medidas que foram tomadas pelo governo. Em boa medida, essas previsóes negativas da populaçáo se concretizaram, conforme os estudos mais recentes vêm comprovando, ou seja, passada a década dourada (2003-2013), parece que os impactos positivos sobre os indicadores sociais advindos de uma conjuntura econômica global favorável às naçôes emergentes foram temporários e agora caminham no sentido contrário (Piketty, Saez e Zucman, 2018; Cepal, 2018; Végh et al., 2019; Oxfam Brasil, 2018; 2019).

No que tange às razóes da desigualdade, novamente, convergente com o conhecimento científico, o olhar multicausal do fenômeno predomina nos cidadãos, que elencam o desemprego, a precariedade do sistema educacional e a corrupção como os principais vilóes. Porém, o ordenamento desses fatores tende a variar conforme os grupos de renda dos respondentes, isto é, seguindo o mesmo padrão divergente já identificado nas pesquisas focadas nas elites do país (Reis, 2000; Silva et al., 2018). Nas soluçôes, como esperado, as alternativas consistem no espelho das causas, ou seja, bem heterogêneas e alinhadas às recomendaçôes dos acadêmicos e organismos multilaterais que atuam no campo. Da mesma forma, a ênfase da população mais pobre se volta ao emprego e aos investimentos governamentais na saúde e assistência social, enquanto a elite deposita as fichas na educação e no combate à corrupção. Em outras palavras, enquanto os primeiros preferem políticas públicas com efeitos imediatos no seu dia a dia, os mais ricos se inclinam para soluçóes sem custos diretos a eles. 
Por fim, a dimensão da tributação também merece destaque, haja vista que os brasileiros se contradizem ao defenderem mais investimentos públicos em políticas sociais, porém são opositores de aumento da carga tributária. Além disso, defendem a progressividade dos impostos, i.e., os mais ricos pagando mais taxas, contudo, tendem a se excluir deste segmento populacional, ou seja, "os ricos são os outros", mesmo que as estatísticas demonstrem o contrário.

Portanto, este texto para discussão alcançou sua finalidade ao abordar o problema da desigualdade no Brasil a partir de uma estratégia analítica original no caso brasileiro, o que trouxe reflexóes novas para o avanço da compreensão sobre esse fenômeno complexo e dinâmico, mas também para qualificar o debate sobre os limites e possibilidades de enfrentamento por parte da administração pública. Isso possibilita ainda entendermos como a desigualdade é reproduzida e/ou como pode ser transformada. Analisar as preferências e os posicionamentos dos cidadãos ajuda a avaliar os possíveis apoios e/ou barreiras às iniciativas de líderes políticos e dirigentes públicos de inserção desse problema na agenda governamental e, principalmente, à capacidade de avançar na implementaçấo de propostas de soluçóes.

Como agenda futura de investigação, vislumbra-se dois caminhos complementares. Um envolve a continuidade de pesquisas de opinião pública com a finalidade de medir se essas visóes se alteram no tempo, uma vez que as percepçóes de desigualdades são afetadas tanto por fatores endógenos (Lavinas et al., 2014) quanto por choques exógenos, tais como a crise econômica ou uma operação de combate à corrupção de larga escala como a Operaçáo Lava Jato, por exemplo. O outro se direciona a comparar os resultados da pesquisa com cidadãos e as respostas das elites decisórias do país, políticas e burocráticas, de modo a propiciar condiçóes para análise de alinhamentos ou conflitos entre as visóes da populaçáo e de seus dirigentes.

\section{REFERÊNCIAS}

AFONSO, J. R. et al. Tributaçáo e desigualdade. Belo Horizonte: Letramento, 2017.

ASSOUAD, L.; CHANCEL, L.; MORGAN, M. Extreme inequality: evidence from Brazil, India, the Middle East, and South Africa. AEA Papers and Proceedings, v. 108, p. 119-23, 2018. 
ATKINSON, A. B. Desigualdade: o que pode ser feito? São Paulo: Editora Leya, 2016.

CATTANI, A. Desigualdades socioeconômicas: conceitos e problemas de pesquisa. Sociologias, n. 18, p. 74-99, 2007.

CEPAL - COMISSÃO ECONÔMICA PARA A AMÉRICA LATINA E O CARIBE. Horizons 2030: equality at the center of sustainable development. Santiago: Cepal, 2016.

Panorama social da América Latina 2017. Santiago: Cepal, 2018. 33 p.

FERNANDES, R.; CAMPOLINA, B.; SILVEIRA, F. Imposto de Renda e distribuiçáo de renda no Brasil. Brasília: Ipea, 2019. (Texto para Discussão, n. 2449).

FUENTES-NIEVA, R.; GALASSO, N. Working for the Few: political capture and economic inequality. Oxfam Brasil, 2014.

GALOR, O. Inequality and economic development: an overview. Providence: Brown University, 2009. (Working Paper, n. 2009-3).

GUPTA, M. S. Does corruption affect income inequality and poverty? Washington, D.C.: International Monetary Fund, 1998.

JONG-SUNG, Y.; KHAGRAM, S. A Comparative Study of Inequality and Corruption. American Sociological Review, v. 70, n. 1, p. 136-157, 2005.

LAVINAS, L. et al. Percepçóes sobre desigualdade e pobreza: o que pensam os brasileiros da política social. Rio de Janeiro: Letra e Imagem, 2014.

LAWSON, M.; MARTIN, M. The commitment to reducing inequality index 2018: a global ranking of governments based on what they are doing to tackle the gap between rich and poor. Cowley: Oxford, 2018.

LEO - LATIN AMERICAN ECONOMIC OUTLOOK. Development in Transition. Boulogne Billancourt: Leo, 2019.

LEVIN, K. et al. Overcoming the tragedy of super wicked problems: constraining our future selves to ameliorate global climate change. Policy Sciences, v. 45, n. 2, p. 123-152, 2012.

MCCARTY, N.; POOLE, K. T.; ROSENTHAL, H. Polarized America: the dance of ideology and unequal riches. Lausana: Walras-Pareto Lectures, 2006.

MEDEIROS, M.; SOUZA, P. Gasto público, tributos e desigualdade de renda no Brasil. Brasília: Ipea. 2013.

A estabilidade da desigualdade no Brasil entre 2006 e 2012: resultados adicionais. Pesquisa e Planejamento Econômico, Rio de Janeiro, v. 46, n. 3, 2016. 
MOORE, M.; HOSSAIN, N. Elites, poverty and public policy. In: REIS, J.; MOORE, M. Elite perceptions of poverty and inequality. New York: Zed Books, 2005.

NERI, M. Qual foi o impacto da crise sobre pobreza e distribuiçáo de renda. Rio de Janeiro: FGV, 2018.

OCDE - ORGANISM FOR ECONOMIC CO-OPERATION AND DEVELOPMENT. Income distribution and poverty in selected OECD Countries. Paris: OCDE, 2008. (Working Paper, n. 189).

. In it together: why less inequality benefits all. Paris: OECD, 2015.

Broken social elevator? How to promote social mobility. Paris: OECD, 2018.

OXFAM BRASIL. A distância que nos une: um retrato das desigualdades brasileiras. São Paulo: Oxfam Brasil, 2017.

. País estagnado: um retrato das desigualdades brasileiras. São Paulo: Oxfam Brasil, 2018.

Public good or private wealth? Methodology note. São Paulo: Oxfam Brasil, 2019.

OXFAM BRASIL; DATAFOLHA. Nós e as desigualdades: percepçôes sobre desigualdades no Brasil. São Paulo: Oxfam Brasil; Datafolha, 2017.

. Nós e as desigualdades: percepções sobre desigualdades no Brasil. São Paulo: Oxfam Brasil; Datafolha, 2019.

PIKETTY, T. O capital no século XXI. 1 Ed. Rio de Janeiro: Intrínseca, 2014.

PIKETTY, T.; SAEZ, E.; ZUCMAN, G. World inequality report 2018. Paris: World Inequality Lab, 2018.

REIS, E. P. Percepçóes da elite sobre pobreza e desigualdade. Revista brasileira de ciências sociais, v. 15 , n. 42, p. 143-152, 2000.

REIS, J.; MOORE, M. Elite perceptions of poverty and inequality. New York: Zed Books, 2005.

SEEKING, J. Inequality, popular attitudes and elite ideology in Africa: the case of social protection. In: UNRISD CONFERENCE OVERCOMING INEQUALITIES IN A FRACTURED WORLD: BETWEEN ELITE POWER AND SOCIAL MOBILIZATION, 2018, Geneva, Switzerland. Anais... Geneva: UNRISD, 8-9 nov. 2018.

SILVA, G. M. et al. Elites' Perceptions of Inequality. UNRISD CONFERENCE OVERCOMING INEQUALITIES IN A FRACTURED WORLD: BETWEEN ELITE POWER AND SOCIAL MOBILIZATION, 2018, Geneva, Switzerland. Anais... Geneva: UNRISD, 8-9 nov. 2018.

SODRÉ, F. R. A. Os impactos da corrupçáo no desenvolvimento humano, desigualdade de renda e pobreza dos municípios brasileiros. Recife: UFPE, 2014. 
TRANSPARENCY INTERNATIONAL. Corruption Perceptions Index 2018. Berlin: Transparency International, 2019.

VÉGH, C. A. et al. (2019). Effects of the Business Cycle on Social Indicators in Latin America and the Caribbean: When Dreams Meet Reality. World Bank, Washington, D.C.: World Bank, 2019. (LAC Semiannual Report - April).

VERBA, S. et al. Elites and the Idea of Equality: a comparison of Japan, Sweden, and the United States. Cambridge: Harvard University Press, 1987.

VERBA, S.; ORREN, G. R. Equality in America: the view from the top. Cambridge: Harvard University Press, 1985.

ZÚNIIGA, N. Correlation between corruption and inequality. Bergen: U4 Anti-Corruption Resource Centre, 2017.

\section{BIBLIOGRAFIA COMPLEMENTAR}

CEPAL - COMISSÃO ECONÔMICA PARA A AMÉRICA LATINA E O CARIBE. The inefficiency of inequality 2018. Havana: Cepal, 2019a.

O futuro do crescimento com igualdade no Brasil: ensaios vencedores do concurso em comemoração aos 70 anos da CEPAL. Santiago: Cepal, 2019b. 
Ipea - Instituto de Pesquisa Econômica Aplicada

\section{EDITORIAL}

\section{Coordenação}

Reginaldo da Silva Domingos

Assistente de Coordenação

Rafael Augusto Ferreira Cardoso

\section{Supervisão}

Camilla de Miranda Mariath Gomes

Everson da Silva Moura

\section{Revisão}

Amanda Ramos Marques

Ana Clara Escórcio Xavier

Clícia Silveira Rodrigues

Idalina Barbara de Castro

Luiz Gustavo Campos de Araújo Souza

Olavo Mesquita de Carvalho

Regina Marta de Aguiar

Hellen Pereira de Oliveira Fonseca (estagiária)

Ingrid Verena Sampaio Cerqueira Sodré (estagiária)

\section{Editoração}

Aeromilson Trajano de Mesquita

Cristiano Ferreira de Araújo

Danilo Leite de Macedo Tavares

Herllyson da Silva Souza

Jeovah Herculano Szervinsk Junior

Leonardo Hideki Higa

\section{Capa}

Danielle de Oliveira Ayres

Flaviane Dias de Sant'ana

\section{Projeto Gráfico}

Renato Rodrigues Bueno

The manuscripts in languages other than Portuguese published herein have not been proofread.

\section{Livraria Ipea}

SBS - Quadra 1 - Bloco J - Ed. BNDES, Térreo

70076-900 - Brasília - DF

Tel.: (61) 2026-5336

Correio eletrônico: livraria@ipea.gov.br 

Composto em adobe garamond pro 12/16 (texto) Frutiger 67 bold condensed (títulos, gráficos e tabelas) Brasilia-DF 



\section{Missão do Ipea}

Aprimorar as políticas públicas essenciais ao desenvolvimento brasileiro por meio da produção e disseminação de conhecimentos e da assessoria ao Estado nas suas decisões estratégicas.

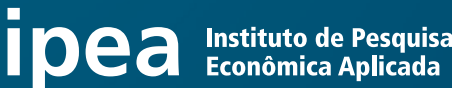 \\ MINISTÉRIO DA \\ ECONOMIA

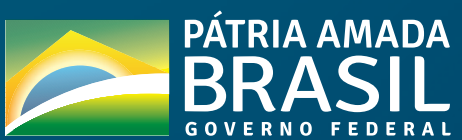

